\title{
Bivariate analysis of basal serum anti-Müllerian hormone measurements and human blastocyst development after IVF
}

\author{
E Scott Sills ${ }^{1,4}$, Gary S Collins ${ }^{2}$, Adam C Brady ${ }^{3}$, David J Walsh ${ }^{4}$, Kevin D Marron ${ }^{4}$, Alison C Peck', \\ Anthony PH Walsh ${ }^{4}$ and Rifaat D Salem ${ }^{1}$
}

\begin{abstract}
Background: To report on relationships among baseline serum anti-Müllerian hormone (AMH) measurements, blastocyst development and other selected embryology parameters observed in non-donor oocyte IVF cycles.

Methods: Pre-treatment AMH was measured in patients undergoing IVF $(n=79)$ and retrospectively correlated to in vitro embryo development noted during culture.

Results: Mean (+/- SD) age for study patients in this study group was $36.3 \pm 4.0$ (range $=28-45$ ) yrs, and mean (+/- SD) terminal serum estradiol during IVF was 5929 +/- $4056 \mathrm{pmol} / \mathrm{l}$. A moderate positive correlation (0.49; 95\% $\mathrm{Cl} 0.31$ to 0.65 ) was noted between basal serum $\mathrm{AMH}$ and number of MIl oocytes retrieved. Similarly, a moderate positive correlation (0.44) was observed between serum $\mathrm{AMH}$ and number of early cleavage-stage embryos $(95 \% \mathrm{Cl}$ 0.24 to 0.61 ), suggesting a relationship between serum $\mathrm{AMH}$ and embryo development in IVF. Of note, serum AMH levels at baseline were significantly different for patients who did and did not undergo blastocyst transfer (15.6 vs. $10.9 \mathrm{pmol} / \mathrm{l} ; p=0.029$ ).

Conclusions: While serum $\mathrm{AMH}$ has found increasing application as a predictor of ovarian reserve for patients prior to IVF, its roles to estimate in vitro embryo morphology and potential to advance to blastocyst stage have not been extensively investigated. These data suggest that baseline serum AMH determinations can help forecast blastocyst developmental during IVF. Serum AMH measured before treatment may assist patients, clinicians and embryologists as scheduling of embryo transfer is outlined. Additional studies are needed to confirm these correlations and to better define the role of baseline serum AMH level in the prediction of blastocyst formation.
\end{abstract}

Keywords: serum AMH, IVF, embryo development, blastocyst transfer

\section{Background}

Anti-Müllerian hormone (AMH), a dimeric glycoprotein member of the transforming growth factor- $\beta$ superfamily, is a product of the granulosa compartment involved in regulation of early ovarian follicular growth and cyclic follicular selection [1,2]. AMH has a highly conserved promoter region and plays a crucial role in mammalian reproduction [3]. Recent data have identified serum $\mathrm{AMH}$ as a useful marker for ovarian reserve, as it correlates with number of primordial follicles and declines

\footnotetext{
* Correspondence: dr.sills@prc-ivf.com

'Division of Reproductive Endocrinology, Pacific Reproductive Center; Irvine, California, USA

Full list of author information is available at the end of the article
}

with advanced reproductive age [4]. AMH is favoured as an ovarian reserve test because of its relative constancy throughout the menstrual cycle [5,6], and its tendency to be unchanged despite GnRH-agonist pituitary downregulation [7] or pregnancy [8]. These aspects of AMH have encouraged its use before treatment to elucidate diminished reserve associated with ovarian ageing $[9,10]$. However, a less well-studied application for pre-IVF serum AMH is its ability to forecast the developmental potential of embryos derived from IVF. If pre-treatment AMH levels could assist in the choice between $\mathrm{d} 3 \mathrm{vs}$. $\mathrm{d} 5$ transfer, this would better manage patient expectations and help establish provisional embryo transfer schedules. By correlating embryo morphology noted during in vitro 
culture with serum AMH levels measured before planned blastocyst transfer in IVF patients, the present investigation sought to clarify this question.

\section{Methods \\ Study patients}

Between September 2009 - December 2009, serum AMH levels were measured in patients $(n=79)$ commencing non-donor gamete IVF at a single centre. All serum samples were collected during the early follicular phase $(d \leq 7)$ within three months of controlled ovarian hyperstimulation for IVF. Treatment cycles incorporating frozen embryo transfer were excluded. All patients were in good general health and had normal pre-treatment laboratory testing; each patient was assessed by a consultant physician before IVF and written informed consent was obtained prior to study enrolment. Normal sperm concentration, motility, and morphology was observed for each male partner in this study group, and sperm DNA fragmentation analysis confirmed sperm chromatin fragmentation was $<25 \%$. While this sample included no severe male factor cases, a limited number of couples $(n=3)$ requested "upfront ICSI" on an individual basis. All patients in this study were non-smokers. For females, baseline (pre-treatment) serum AMH values were correlated with the following intercycle parameters: Female patient age (yrs), terminal serum $E_{2}$, total number of oocytes retrieved, number of metaphase II (MII) oocytes retrieved, number of early cleavage stage embryos produced after fertilisation, number of embryos with $\geq 7$ cells present on $\mathrm{d} 3$, and the number of blastocysts that had developed by $\mathrm{d} 5$. Neither basal antral follicle count, serum d3 FSH, nor ampoules/type of gonadotropins consumed during follicular recruitment were recorded for analysis, although clinical pregnancy rate was also noted as a secondary endpoint. Because this was a retrospective study, institutional review board approval was not required. For all patients, pituitary downregulation was achieved with twice-daily $200 \mathrm{mcg}$ intranasal nafarelin acetate (Synarel ${ }^{\circledR}$; Phamacia Ltd., Milton Keynes, UK) followed by gonadotropin administration and office monitoring as described previously [11].

\section{AMH assay procedure}

Each patient provided one specimen by peripheral venipuncture which was assayed for AMH in duplicate via MIS/AMH ELISA DSL-10-14400 (Diagnostic Systems Laboratories, Inc.; Webster, Texas USA). This device used an enzymatically amplified two-site immunoassay where standards, controls, and samples were incubated in microtitration wells coated with anti-AMH antibody. After incubation and washing, anti-AMH detection antibody labeled with biotin was added to each well. Streptavidin horseradish peroxidase (HRP) was added to wells following a secondary incubation/washing. Tetramethylbenzidine (TMB) was introduced after a third incubation and washing procedure, followed by addition of an acidic stopping solution. Enzymatic turnover of substrate was determined by dual wavelength absorbance measurement at $450 \mathrm{~nm}$ and $600-630 \mathrm{~nm}$ (measured absorbance is directly proportional to sample AMH content). Standards were processed concurrently with experimental samples to determine serum AMH for each specimen. The minimum detectable level of AMH in serum was $0.04 \mathrm{pmol} /$ $\mathrm{ml}$, with intra- and interassay coefficients of variation of $<5 \%$ and $<8 \%$, respectively.

\section{Assessment of embryo development}

Immediately after retrieval oocyte-cumulus complexes were placed into Universal IVF medium (MediCult; Jyllinge, Denmark), with insemination (including ICSI) also carried out using this reagent under washed liquid paraffin oil (MediCult, Denmark). Culture was maintained to d5 in microdrops of BlastAssist media I and II (MediCult, Denmark) under washed paraffin oil in a $5 \% \mathrm{CO} 2+5 \% \mathrm{O} 2$ atmosphere at $95 \%$ humidity. Embryo development was observed via multi-port inverted optical microscope fitted with Hoffman contrast modulation (Nikon TE300; Tokyo, Japan). Daily assessments of embryos were recorded at 200-400× magnification; d5 blastocysts selected for in utero transfer featured a well-defined inner cell mass and highly cellular, expanding trophoectoderm [12].

\section{Statistical analysis}

The Mann-Whitney test was used to test differences, as the outcomes were skewed (non-normal distribution). Differences measured at $p<0.05$ were considered significant; differences between groups were reported as pseudomedians (i.e., median of differences between samples).

\section{Results}

In this study group, median (IQR 25;75) female patient age was 36.1 (33.7; 39.4) overall; patient ages among those who did $(n=27)$ and did not $(n=52)$ attain clinical pregnancy after embryo transfer were $34.8(32.2 ; 37.7)$ and $37.1(34.2 ; 40.3)$, respectively $(p=0.073)$. No analysed IVF cycles were complicated by ovarian hyperstimulation syndrome and there were no cycle cancellations during the study interval. As summarised in Table 1, pretreatment serum AMH was significantly higher among patients attaining blastocyst transfer compared to those who did not $(15.6$ [10.7;22.9] vs. 10.9 [3.6;19.5]; $p=$ $0.029)$. Consistent with previous reports $[4,5]$, our data confirmed the inverse relationship between age and basal serum AMH (correlation -0.48; 95\% CI -0.63 to -0.29). Figure 1 depicts the relationship between patient age and capacity for blastocyst transfer. As shown in Figure 2, median pre-treatment serum AMH levels were 
Table 1 Blastocyst development in vitro compared with basal serum AMH and selected clinical/embryology parameters among IVF patients $(n=79)$

\begin{tabular}{|c|c|c|c|c|}
\hline & $\begin{array}{c}\text { No blastocyst } \\
(n=46)\end{array}$ & $\begin{array}{c}\text { Blastocyst } \\
(n=33)\end{array}$ & $\begin{array}{c}\text { Difference } \\
(95 \% \mathrm{Cl})\end{array}$ & $p^{1}$ \\
\hline Serum AMH $(\mathrm{pmol} / \mathrm{l})$ & $10.9(3.6,19.5)$ & $15.6(10.7,22.9)$ & $4.9(0.6$ to 8.9$)$ & 0.029 \\
\hline Age (yrs) & $35.9(33.5,39.2)$ & $37.3(33.7,40.3)$ & $0.7(-1.4$ to 2.7$)$ & 0.509 \\
\hline Terminal $E_{2}(p m o l / l)$ & $4084(2996,5164)$ & $7282(3572,10770)$ & 2335 (-260 to 6361) & 0.121 \\
\hline Oocytes retrieved (total $n$ ) & $7(4,17)$ & $10(7,13)$ & $3(1,5)$ & 0.004 \\
\hline MIl oocytes retrieved $(n)$ & $5(3,8)$ & $9(6,12)$ & $3(2,5)$ & 0.006 \\
\hline Early cleavage embryos $(n)$ & $3.5(2,6)$ & $6(5,9)$ & $3(2,4)$ & 0.002 \\
\hline$\geq 7$-cell embryos on d3 (n) & $1.5(0,3)$ & $2(1,4)$ & $1(0,2)$ & 0.07 \\
\hline
\end{tabular}

'by Mann-Whitney $U$ test

Notes: All data presented as mean (IQR 25,75); $\mathrm{AMH}=$ anti-Müllerian hormone; $\mathrm{E}_{2}=$ estradiol;

MII = metaphase II; $\mathrm{d} 3=$ post-fertilisation day three

significantly different for patients who did undergo blastocyst transfer and those who did not (15.6 vs. 10.9 $\mathrm{pmol} / \mathrm{l} ; p=0.029$ by Mann-Whitney test). While median patient age was higher among patients who underwent blastocyst transfer compared to patients who did not, this difference was not significant (37.3 vs. 35.9; $p=$ 0.509). Moreover, basal serum AMH levels were generally higher among patients who attained a clinical pregnancy, but this difference was not significant (16.4 vs. 11.4 $\mathrm{pmol} / \mathrm{l} ; p=0.14$ by Mann-Whitney test). In this study population, the observed clinical pregnancy rate was 27/ 79 per embryo transfer $(34.2 \%)$.

\section{Discussion}

This investigation is the first to show a positive, albeit weak, correlation between baseline serum AMH levels

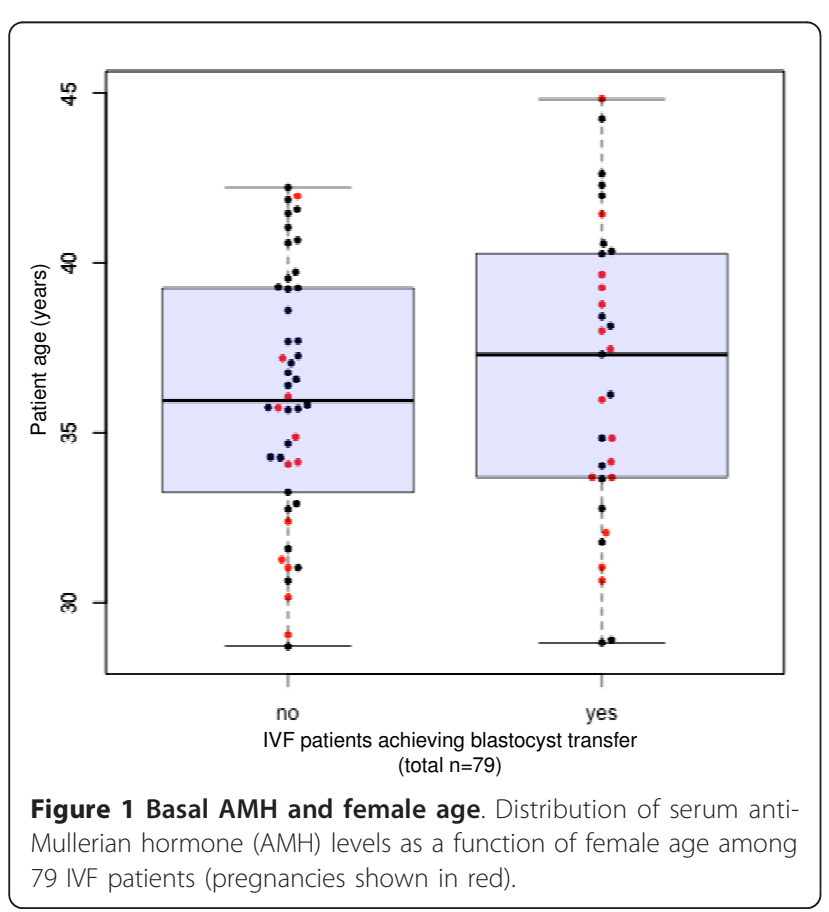

and subsequent blastocyst development during IVF. Although serum AMH has found increasing application as a predictor of ovarian reserve, its role in forecasting in vitro embryo morphology and developmental potential to the blastocyst stage is still emerging. For example, Riggs et al [13] found AMH to be a useful biomarker to predict low vs. high responders among oocyte donors, but not predictive of embryo morphology or pregnancy outcome in the recipient population. Similarly, while an earlier study reported basal serum AMH as useful in predicting oocyte number and quality, further cleavage up to the blastocyst stage was not affected by AMH [14]. In contrast, the current investigation suggests that baseline serum AMH determinations can indeed be extended to estimate blastocyst developmental potential during IVF.

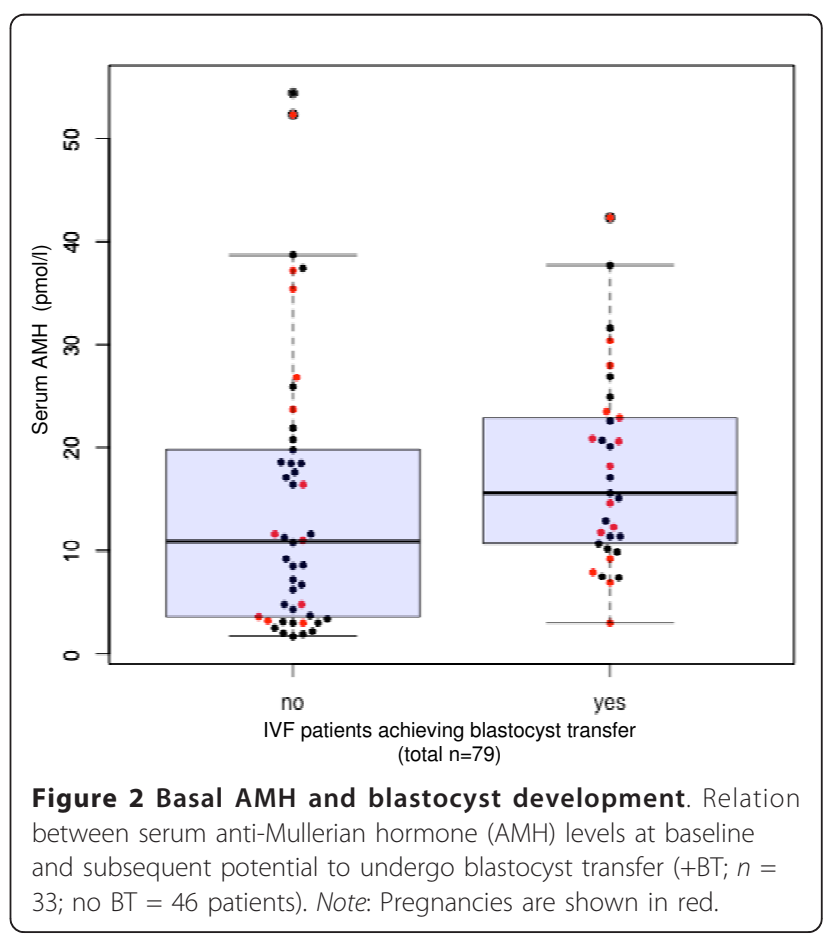


A trend of somewhat lower patient age where no blastocyst transfer was possible represents an unexpected finding from our study, and underscores the limitations of using patient age alone as a method to predict blastocyst development.

Clinicians and researchers continue to search for improved methods to estimate ovarian reserve and predict reproductive outcome. Serum AMH may help solve this challenge, as it is maximal in females at puberty but progressively decays throughout reproductive life $[15,16]$. Indeed, physiologic menopause or surgical removal of functional ovaries will render serum AMH essentially undetectable within days $[4,17]$. More recently, specific polymorphisms of the AMH receptor have been implicated as additional modulators of sex-steroid activity [18]. Early determination of reserve is useful not only because this information helps guide patient counselling, but it also assists in calibrating the gonadotropin doses for IVF patients. Risks of poor follicular recruitment [19] and ovarian hyperstimulation $[20,21]$ would be minimised by accurate and reliable prediction of ovarian response in IVF. Since serum AMH levels might help estimate ovarian response for non-IVF patients as well [22], this test has emerged as an increasingly important element of basic fertility assessments. When best to assess serum AMH has also been studied, but baseline measurement seems to be the most predictive marker for ovarian response [23]. Whether or not serum AMH can be validated as the definitive biophysiologic test to predict the age of menopause remains the subject of active study and debate $[24,25]$.

Several limitations of this research should be noted. First, we did not stratify study subjects by infertility aetiology, although evidence suggests that different types of reproductive pathology might impact serum AMH in different ways. For example, ovarian response to gonadotropins is often attenuated in the setting of endometriosis, and serum AMH is reduced in fertility patients as a function of severity of the disease [26]. In contrast, polycystic ovary syndrome (PCOS) is associated with abnormally increased follicular numbers and relatively high serum AMH. This enhanced AMH production by granulosa cells in women with PCOS may be a dysfunctional manifestation of impaired access of FSH to the follicular compartment [27]. This retrospective study did not take these factors into account. Additionally, we should note that while a trend of higher median serum AMH levels was observed among patients who conceived compared to those who did not attain pregnancy, our study was not designed to detect this difference.

\section{Conclusions}

Although others have focused on d3 serum AMH levels to predict clinical pregnancy [28], the present study aimed to assess an important intermediate IVF endpoint-blastocyst development. We confirmed a moderate positive correlation between AMH and total number of retrieved oocytes, as well as the number of MII oocytes. Our data from blastocyst culture agree with and extend previous AMH research, where AMH was noted to have a highly significant correlation with number of oocytes retrieved and fertilised where $\mathrm{d} 2$ and $\mathrm{d} 3$ embryo transfer occurs [29]. This investigation also found pre-treatment serum AMH to have moderate positive correlations with development of early cleavagestage embryos and embryos with at least 7-cells on $\mathrm{d} 3$, observations generally consistent with previous reports $[29,30]$. The observed positive correlation between basal serum AMH and subsequent blastocyst formation will require larger sampling to refine the role of $\mathrm{AMH}$ in estimating embryo transfer strategies.

\section{Author details}

${ }^{1}$ Division of Reproductive Endocrinology, Pacific Reproductive Center; Irvine, California, USA. ${ }^{2}$ Centre for Statistics in Medicine, Wolfson College Annexe, University of Oxford; Oxford, UK. ${ }^{3}$ Department of Medicine, University of Massachusetts School of Medicine; Worcester, Massachusetts, USA. ${ }^{4}$ Division of Reproductive Endocrinology, The Sims Institute/Department of Obstetrics \& Gynaecology, School of Medicine, Royal College of Surgeons in Ireland; Dublin, Ireland.

\section{Authors' contributions}

ESS was lead investigator and organised the manuscripts; GSC assisted in study design and provided statistical analysis; ACB collected clinical and laboratory data; DJW, ACP and APHW were consultant physicians with oversight of the clinical programme; RDS was Chief-of-Service and principal project supervisor. All authors read and approved the final version.

\section{Competing interests}

The authors declare that they have no competing interests.

Received: 21 October 2011 Accepted: 2 December 2011 Published: 2 December 2011

\section{References}

1. Durlinger $A L$, Visser JA, Themmen AP: Regulation of ovarian function: the role of anti-Müllerian hormone. Reproduction 2002, 124:601-609.

2. di Clemente N, Josso N, Gouédard L, Belville C: Components of the antiMüllerian hormone signaling pathway in gonads. Mol Cell Endocrinol 2003, 211:9-14.

3. Pask AJ, Whitworth DJ, Mao CA, Wei KJ, Sankovic N, Graves JA, Shaw G, Renfree MB, Behringer RR: Marsupial anti-Mullerian hormone gene structure, regulatory elements, and expression. Biol Reprod 2004, 70:160-167.

4. van Rooij IA, Broekmans FJ, Scheffer GJ, Looman CW, Habbema JD, de Jong FH, Fauser BJ, Themmen AP, te Velde ER: Serum antimullerian hormone levels best reflect the reproductive decline with age in normal women with proven fertility: a longitudinal study. Fertil Steril 2005, 83:979-987.

5. La Marca A, Stabile G, Artenisio AC, Volpe A: Serum anti-Mullerian hormone throughout the human menstrual cycle. Hum Reprod 2006, 21:3103-3107.

6. Liberty G, Ben-Chetrit A, Margalioth EJ, Hyman JH, Galoyan N, Eldar-Geva T: Does estrogen directly modulate anti-müllerian hormone secretion in women? Fertil Steril 2010, 94:2253-2256.

7. Mohamed KA, Davies WA, Lashen H: Antimüllerian hormone and pituitary gland activity after prolonged down-regulation with goserelin acetate. Fertil Steril 2006, 86:1515-1517. 
8. La Marca A, De Leo V, Giulini S, Orvieto R, Malmusi S, Giannella L, Volpe A Anti-Mullerian hormone in premenopausal women and after spontaneous or surgically induced menopause. I Soc Gynecol Investig 2005, 12:545-548.

9. Visser J: Role of anti-Müllerian hormone in follicle recruitment and maturation. J Gynecol Obstet Biol Reprod (Paris) 2006, 35(5 Pt 2):2S30-2S34

10. Sills ES, Alper MM, Walsh AP: Ovarian reserve screening in infertility: practical applications and theoretical directions for research. Eur J Obstet Gynecol Reprod Biol 2009, 146:30-36.

11. Sills ES, Drews CD, Perloe M, Kaplan CR, Tucker MJ: Periovulatory serum human chorionic gonadotropin (hCG) concentrations following subcutaneous and intramuscular nonrecombinant hCG use during ovulation induction: a prospective, randomized trial. Fertil Steril 2001, 76:397-9.

12. Walsh AP, Shkrobot LV, Coull GD, Peirce KL, Walsh DJ, Salma U, Sills ES: Blastocyst transfer for multiple prior IVF failure: a five year descriptive study. Ir Med J 2009, 102:282-285.

13. Riggs R, Kimble T, Oehninger S, Bocca S, Zhao Y, Leader B, Stadtmauer L: Anti-Müllerian hormone serum levels predict response to controlled ovarian hyperstimulation but not embryo quality or pregnancy outcome in oocyte donation. Fertil Steril 2011, 95:410-412.

14. Ebner T, Sommergruber M, Moser M, Shebl O, Schreier-Lechner E, Tews G: Basal level of anti-Müllerian hormone is associated with oocyte quality in stimulated cycles. Hum Reprod 2006, 21:2022-6.

15. Lee MM, Donahoe PK, Hasegawa T, Silverman B, Crist GB, Best S, Hasegawa Y, Noto RA, Schoenfeld D, MacLaughlin DT: Mullerian inhibiting substance in humans: normal levels from infancy to adulthood. $J$ Clin Endocrinol Metab 1996, 81:571-576.

16. Guibourdenche J, Lucidarme N, Chevenne D, Rigal O, Nicolas M, Luton D, Léger J, Porquet D, Noël M: Anti-Müllerian hormone levels in serum from human foetuses and children: pattern and clinical interest. Mol Cell Endocrinol 2003, 211:55-63.

17. van Rooij IA, Tonkelaar I, Broekmans FJ, Looman CW, Scheffer GJ, de Jong $\mathrm{FH}$, Themmen AP, te Velde ER: Anti-mullerian hormone is a promising predictor for the occurrence of the menopausal transition. Menopause 2004, 11:601-606.

18. Rigon C, Andrisani A, Forzan M, D'Antona D, Bruson A, Cosmi $E_{1}$ Ambrosini G, Tiboni GM, Clementi M: Association study of AMH and AMHRII polymorphisms with unexplained infertility. Fertil Steril 2010, 94:1244-1248.

19. Nicopoullos JD, Abdalla $\mathrm{H}$ : Poor response cycles: when should we cancel? Comparison of outcome between egg collection, intrauterine insemination conversion, and follow-up cycles after abandonment. Fertil Steril 2011, 95:68-71.

20. Alper MM, Smith LP, Sills ES: Ovarian hyperstimulation syndrome: current views on pathophysiology, risk factors, prevention, and management. $J$ Exp Clin Assist Reprod 2009, 6:3.

21. Nakhuda GS, Douglas NC, Thornton MH, Guarnaccia MM, Lobo R, Sauer MV: Anti-Müllerian hormone testing is useful for individualization of stimulation protocols in oocyte donors. Reprod Biomed Online 2010, 20:42-47.

22. Li HWR, Yeung WSB, Lau EYL, Ho PCH, Ng EHY: Evaluating the performance of serum antimullerian hormone concentration in predicting the live birth rate of controlled ovarian stimulation and intrauterine insemination. Fertil Steril 2010, 94:2177-2181.

23. Lee JR, Kim SH, Kim SM, Jee BC, Ku SY, Suh CS, Choi YM, Kim JG, Moon SY: Anti-Mullerian hormone dynamics during controlled ovarian hyperstimulation and optimal timing of measurement for outcome prediction. Hum Reprod 2010, 25:2597-2604

24. Lambalk CB, van Disseldorp J, de Koning CH, Broekmans FJ: Testing ovarian reserve to predict age at menopause. Maturitas 2009, 63:280-291.

25. Tehrani FR, Solaymani-Dodaran M, Azizi F: A single test of antimullerian hormone in late reproductive-aged women is a good predictor of menopause. Menopause 2009, 16:797-802.

26. Shebl O, Ebner T, Sommergruber M, Sir A, Tews G: Anti muellerian hormone serum levels in women with endometriosis: a case-control study. Gynecol Endocrinol 2009, 25:713-716.

27. Desforges-Bullet V, Gallo C, Lefebvre C, Pigny P, Dewailly D, CatteauJonard S: Increased anti-Müllerian hormone and decreased FSH levels in follicular fluid obtained in women with polycystic ovaries at the time of follicle puncture for in vitro fertilization. Fertil Steril 2010, 94:198-204.
28. Wu CH, Chen YC, Wu HH, Yang JG, Chang YJ, Tsai HD: Serum antiMüllerian hormone predicts ovarian response and cycle outcome in IVF patients. J Assist Reprod Genet 2009, 26:383-389.

29. Majumder K, Gelbaya TA, Laing I, Nardo LG: The use of anti-Müllerian hormone and antral follicle count to predict the potential of oocytes and embryos. Eur J Obstet Gynecol Reprod Biol 2010, 150:166-170.

30. La Marca A, Broekmans FJ, Volpe A, Fauser BC, Macklon NS, ESHRE Special Interest Group for Reproductive Endocrinology-AMH Round Table: AntiMullerian hormone (AMH): what do we still need to know? Hum Reprod 2009, 24:2264-2275.

doi:10.1186/1477-7827-9-153

Cite this article as: Sills et al.: Bivariate analysis of basal serum antiMüllerian hormone measurements and human blastocyst development after IVF. Reproductive Biology and Endocrinology 2011 9:153.

\section{Submit your next manuscript to BioMed Central and take full advantage of:}

- Convenient online submission

- Thorough peer review

- No space constraints or color figure charges

- Immediate publication on acceptance

- Inclusion in PubMed, CAS, Scopus and Google Scholar

- Research which is freely available for redistribution

Submit your manuscript at www.biomedcentral.com/submit
Ciomed Central 